\title{
Treatment failure in a typhoid patient infected with nalidixic acid resistant S. enterica serovar Typhi with reduced susceptibility to Ciprofloxacin: a case report from Cameroon
}

\author{
Njinkeng J Nkemngu*1,2, Etienne DN Asonganyi ${ }^{2,3}$ and Anna L Njunda ${ }^{4}$
}

\author{
Address: ${ }^{1}$ St. John's Maternity and Hospital, Fiango, Kumba, Cameroon, ${ }^{2}$ St. Joseph's medical Centre, Yoke-Muyuka, Cameroon, ${ }^{3}$ University \\ Teaching Hospital, University of Yaounde I, Yaounde, Cameroon and ${ }^{4}$ Faculty of Health Sciences, University of Buea, Buea, Cameroon \\ Email: Njinkeng J Nkemngu* - jnkemngu@yahoo.com; Etienne DN Asonganyi -ngunyie@yahoo.com; \\ Anna L Njunda - ann_njunda@yahoo.com \\ * Corresponding author
}

Published: 21 June 2005

BMC Infectious Diseases 2005, 5:49 doi:10.1 186/147/-2334-5-49

This article is available from: http://www.biomedcentral.com/I47/-2334/5/49

(C) 2005 Nkemngu et al; licensee BioMed Central Ltd.

This is an Open Access article distributed under the terms of the Creative Commons Attribution License (http://creativecommons.org/licenses/by/2.0), which permits unrestricted use, distribution, and reproduction in any medium, provided the original work is properly cited.
Received: 15 February 2005

Accepted: 21 June 2005

\begin{abstract}
Background: Fluoroquinolones or third generation cephalosporins are the drugs of choice for the treatment of typhoid fever. Treatment failure with fluoroquinolones has been reported in Asia and Europe. We report a case of ciprofloxacin treatment failure in typhoid fever in Cameroon.

Case presentation: A 29-year-old female patient with suspected typhoid fever from Kumba, Cameroon, yielded growth of Salmonella enterica serovar Typhi in blood culture. The isolate was resistant to nalidixic acid but sensitive to ciprofloxacin by disc diffusion test. However, the patient did not respond to treatment with ciprofloxacin, although the isolate was apparently susceptible to ciprofloxacin.
\end{abstract}

Conclusion: Treatment failure with ciprofloxacin in our case indicates the presence of nalidixic acid resistant S. enterica serovar Typhi (NARST) with reduced susceptibility to ciprofloxacin in Cameroon (Central Africa).

\section{Case presentation}

A 29-year-old woman from Kumba, Cameroon, was admitted in January 2004 to St. John's Hospital and Maternity, Kumba, with a five-day history of fever, emesis, poorly localized abdominal discomfort, myalgias and hepatosplenomegaly. Her total leukocyte count was $1.7 \times$ $10^{9} / \mathrm{l}$, (neutrophils 51\%, lymphocytes $43 \%$, monocytes $5 \%$ ). Urinalysis was normal and thin and thick film examinations of the peripheral blood were negative for malaria. The patient also tested negative for HIV. A blood Widal test however, showed a titre of 80 against "O" (somatic) antigen and 160 against the "H" (flagella) antigen of Salmonella enterica serovar Typhi (recommended cut-off titre in our hospital: $\geq 1: 80$ and $\geq 1: 160$ for the " $\mathrm{O}$ " and " $\mathrm{H}$ " antigens respectively). Blood culture grew Salmonella enterica serovar Typhi. Two months prior to her illness, she had suffered from an attack of suspected typhoid fever and had been treated with chloramphenicol $500 \mathrm{mg}$ every 6 hours for 14 days.

Antibiogram of the isolated S. enterica serovar Typhi was performed by disc diffusion techniques as recommended by NCCLS guidelines [1], Minimum inhibitory concentrations (MIC) of nalidixic acid and ciprofloxacin were determined by agar dilution method [2]. The antibiotic discs used included ampicillin $10 \mu \mathrm{g}$ (Beecham), co-trimoxa- 
zole 1.25/23.75 $\mu \mathrm{g}$ (Roche), chloramphenicol $30 \mu \mathrm{g}$ (Antibioticos SA), ciprofloxacin $5 \mu \mathrm{g}$ (Bayer), nalidixic acid $30 \mu \mathrm{g}$ (Sigma) and ceftriaxone $30 \mu \mathrm{g}$ (Roche). The isolate was found resistant to nalidixic acid, ampicillin, co-trimoxazole and chloramphenicol, but susceptible to ceftriaxone and ciprofloxacin by disc diffusion test. The MICs of ciprofloxacin and nalidixic acid were $0.5 \mu \mathrm{g} / \mathrm{ml}$ and $32.0 \mu \mathrm{g} / \mathrm{ml}$ respectively. The patient remained febrile after 7 days of oral administration of $500 \mathrm{mg}$ ciprofloxacin every 12 hours. Thereafter, the patient was administered $1 \mathrm{~g}$ ceftriaxone every 12 hours intravenously, which rendered her afebrile within four days. Treatment was continued for another 3 days. The patient did not relapse on follow-up.

\section{Conclusion}

The emergence of multi-drug-resistant Salmonella enterica serovar Typhi (MDRST) strains was first reported in the $80 \mathrm{~s}$, in Asia. Sporadic cases of ciprofloxacin treatment failure in typhoid fever have been reported in Europe and more recently, in Asia $[3,4]$. Our report indicates that MDRST and nalidixic acid resistant Salmonella enterica serovar Typhi (NARST) strains are now appearing in Cameroon, Central Africa. NARST have also been reported in East Africa [5]. However, treatment failure with fluoroquinolones in patients affected by the NARST strains in East Africa has not been described, although several reports suggest that the clinical response to fluoroquinolones in patients infected with NARST may be inferior to the response in those infected with nalidixic acid-susceptible strains [[4-11], this report].

There may be single or multi-mutations in the quinoloneresistance-determining region of either DNA gyrase (gyrA or gyrB or both) or DNA topoimerase IV (parC and parE or both) or both enzymes, which cause resistance of Salmonella enterica serovar Typhi strains to fluoroquinolone $[5,9]$. Resistance may also be due to other mechanisms such as decreased permeability and active efflux of the antimicrobial agents. Previous studies have shown that MDRST strains in East Africa were related to earlier drugsusceptible isolates but were unrelated to MDRST isolates from Asia. [10]. MDRST and NARST isolates in Central African may be unrelated to those earlier reported in Asia, Europe and east Africa [3-11].

Ceftriaxone is an alternative drug in cases of quinolone resistant typhoid fever. However, there have been reports of high-level resistance to ceftriaxone $(\mathrm{MIC}=64 \mathrm{mg} / \mathrm{l})$ in both Salmonella enterica serovar Typhi and Paratyphi A [3]. Third generation cephalosporins are also expensive (a treatment course with parental Ceftriaxone is six times more expensive compared to oral ciprofloxacin in Cameroon), and regularly not available. The efficacy of azithromycin, which was recently shown to be an effective alternative treatment for uncomplicated enteric fever due to MDRST, needs to be confirmed in patients with typhoid fever due to a NARST strain [12]. Improved hygienic conditions and effective surveillance methods to monitor newly emerged MDRST and NARST strains in Africa and other enteric fever endemic regions are of utmost importance.

\section{Authors' contributions}

NJN conceived and coordinated of the study, drafted the manuscript, analyzed the microbial tests results. EDNA helped in the drafting of the manuscript and analysis of microbial test results. ALN helped to draft the manuscript. All authors read and approved the final manuscript.

\section{Competing interests}

The author(s) declare that they have no competing interests.

\section{Financial support \\ None}

\section{Acknowledgements}

We thank T. Fosi-Mbantenkhu, and Ngang K. Che for critical reading of the manuscript. Written consent was obtained from the patient for publication of the study.

\section{References}

I. National Committee for Clinical Laboratory Standards: Performance standards for antimicrobial disk susceptibility test. National Committee for Clinical Laboratory Standards, Wayne, Pa 1999. Ninth information supplement MI00-S9

2. National Committee for Clinical Laboratory Standards: Methods for dilution antimicrobial susceptibility test for bacterial that grow aerobically. Approved standard M7-A5. National Committee forclinical Laboratory Standards, Wayne, Pa 2000.

3. Parry CM, Hien TT, Dougan G, White NJ, Farrar Jj: Typhoid fever. N Engl J Med 2002, 347: I770-I 782.

4. Butt Tariq, Ahmad Rifat Nadeem, Mahmood Abid, Zaidi Sabeen: Ciprofloxacin Treatment Failure in Typhoid Fever Case, Pakistan. Emerging Infectious Diseases 2003, 9:1621-1622.

5. Kariuki S, Revathi G, Muyodi J, Mwituria J, Munyalo A, Mirza S, Hart CA: Characterization of multidrug-resistant typhoid outbreaks in Kenya. Clin Microbiol 2004, 42: |477-| 482.

6. Hakanen A, Kotilainen P, Jalava J, Siitonen A: Detection of decreased fluoroquinolone susceptibility and validation of nalidixic acid screening test. J Clin Microbiol 1999, 37:3572-3577.

7. Threlfall EJ, Ward LR: Decreased susceptibility to ciprofloxacin in Salmonella enterica serotype Typhi, United Kingdom. Emerg Infect Dis 200I, 7:448-450.

8. Mehta G, Randhawa VS, Mohapatra NP: Intermediate susceptibility to ciprofloxacin in Salmonella enterica serovar Typhi strains in India. Eur J Clin Microbiol Infect Dis 200I, 20:760-76I.

9. Wain J, Hoa NT, Chinh NT, et al:: Quinolone-resistant Salmonella typhi in Viet Nam: molecular basis of resistance and clinical response to treatment. Clin Infect Dis 1997, 25:1404-10.

10. Kariuki S, Gilks C, Revathi G, Hart CA: Genotypic Analysis of Multidrug-Resistant Salmonella enterica Serovar Typhi, Kenya. Emerg Infect Dis 2000, 6:649-65I.

11. Hakanen A, Kotilainen P, Huovinen P, Helenius H, Siitonen A: Reduced fluoroquinolone susceptibility in Salmonella enterica serotypes in travelers returning from Southeast Asia. Emerg Infect Dis 200I, 7:996-1003.

12. Chinh NT, Parry CM, LY NT, et al.: A Randomized Controlled Comparison of Azithromycin and Ofloxacin for Treatment 
of Multidrug-Resistant or Nalidixic Acid-Resistant Enteric Fever. Antimicrobial Agents Chemother 2000, 44: I855-I859.

\section{Pre-publication history}

The pre-publication history for this paper can be accessed here:

http://www.biomedcentral.com/1471-2334/5/49/prepub

Publish with BioMed Central and every scientist can read your work free of charge

"BioMed Central will be the most significant development for disseminating the results of biomedical research in our lifetime. " Sir Paul Nurse, Cancer Research UK

Your research papers will be:

- available free of charge to the entire biomedical community

- peer reviewed and published immediately upon acceptance

- cited in PubMed and archived on PubMed Central

- yours - you keep the copyright

Submit your manuscript here:

http://www.biomedcentral.com/info/publishing_adv.asp 